Houge Mackenzie, Kerr. Published in the Journal of Sport \& Tourism. October 2014

\title{
The psychological experience of river guiding: exploring the protective frame and implications for guide well-being
}

\author{
Susan Houge Mackenzie ${ }^{a *}$ and John H. Kerr ${ }^{\mathrm{b}}$ \\ ${ }^{a}$ Recreation, Parks, and Tourism Administration Department, California \\ Polytechnic State University, San Luis Obispo, CA 93407, USA; ' ${ }^{\text {School of }}$ \\ Kinesiology, University of British Columbia, 210-6081 University Blvd, Vancouver, \\ BC, Canada V6T 1Z1
}

\begin{abstract}
Adventure tours are a fast-growing segment of the tourism market and guide behaviour has been identified as a critical factor in tourist satisfaction. However, little research has investigated guides' emotional and motivational experiences and implications for psychological well-being. This study analyses critical incidents from autoethnographical data captured during a 10-year span of white-water river guiding in the northern and southern hemispheres. Reversal theory constructs inform analysis of psychological states and emotions experienced throughout guide training, development, and river trip interactions. Factors that may influence guides' 'protective frames', emotions, and motivational states are discussed, along with implications for guide and client well-being.
\end{abstract}

Keywords: adventure experience; autoethnography; guide well-being; guide emotions; reversal theory

\section{Introduction}

Adventure tourism studies have evaluated psychological aspects of tourists' experiences, such as needs, motivations, and emotions, in an effort to enhance tourist satisfaction and marketing efforts (Fluker \& Turner, 2000; Pomfret, 2012; Williams \& Soutar, 2009). Research indicates that intense psychological states and emotions before, during, and after adventure experiences have a pivotal influence on experience quality (Arnould \& Price, 1993; Arnould, Price, \& Otnes, 1999; Buckley, 2012; Carnicelli-Filho, Schwartz, \& Tahara, 2010; Cater, 2006; Holyfield \& Jonas, 2003). In addition, adventure experiences have a range of reported benefits, such as goal achievement; fear management; escaping boredom; enjoyment and meaning; optimal engagement and control; enhanced courage, humility, and sense of purpose; and improved connections to others and the natural world (Brymer \& Gray, 2010; Brymer

*Corresponding author. Email: mackenzi@calpoly.edu 
\& Oades, 2009; Brymer \& Schweitzer, 2012; Coble, Selin, \& Erickson, 2003; Houge Mackenzie, Hodge, \& Boyes, 2011, 2013; Lupton \& Tulloch, 2002; Lyng, 1990; Willig, 2008). Adventure sports have even been recommended as alternative forms of health promotion (Burr, Montelpare, \& Shephard, 2013).

Popular literature suggests that adventure trips may elicit a range of intense positive and negative emotions amongst guides (Bangs \& Kallen, 1989; Krakauer, 1997). This is likely due to adventure guides managing more tasks and emotions than their counterparts in other tourism sectors (Valkonen, 2009). However, ethnographic research has documented that clients have a narrower range of 'acceptable' guide emotions, which include positive displays of enthusiasm, encouragement, bravery, and calm (Buckley, 2010; Jonas, 1999). Negative emotions such as anger, fear, boredom, or aggression are generally considered unacceptable for guides to express. A number of sociological studies also suggest that emotion management and performative, aesthetic, and emotional labour are common issues amongst tour guides (Arnould \& Price, 1993; Arnould et al., 1999; Holyfield, 1999; Sharpe, 2005; Varley, 2011). For example, Holyfield, Jonas, and Zajicek (2005) demonstrated that, in addition to manipulating clients' emotions to enhance the status and wellbeing of their customers, commercial guides also manipulated their own emotions to satisfy personal emotional needs.

Notwithstanding these findings, investigations of subjective experiences in tourism generally, and adventure tourism specifically, are lacking. Two recent reviews highlight these knowledge gaps. Cutler and Carmichael's (2010) extensive review of tourist experience literature highlighted the need to examine the impacts of internal and external factors on affective/emotional dimensions of tourist experiences. In addition, Weber's (2008) review found that adventure tourism scholarship has been primarily based on scholars' preconceived notions and required more qualitative investigations of individuals' subjective adventure experiences. More research on the emotional and motivational dimensions of adventure guide experiences is needed to improve guide well-being, as well as tourist safety and satisfaction (Ap \& Wong, 2001). Investigations of guide experiences are limited and tend to focus explicitly on service quality outcomes (Ap \&Wong, 2001; Mak, Wong, \& Chang, 2011). As a result, the psychological and emotional experiences of adventure guides remain largely unexplored. Understanding these experiences is critical not only for promoting professionalism, customer service, and safety, but also for ensuring guide well-being.

\section{River guides' motivational and emotional experiences}

Guides may play a number of roles in the tourist experience. Early literature on tour guides suggested that they are both pathfinders and mentors, and that their roles are composed of four major components: instrumental, social, interactionary, and communicative (Cohen, 1985). Cohen proposed that professional 
guides undergo phases of development wherein they transition from emphasising the instrumental to the communicative components of their role. These proposed roles were refined into clear guide functions that include acting as environmental and cultural educators, accommodating hosts and ambassadors, social facilitators, and conscientious and inclusive leaders (Pond, 1993). More recent literature has emphasised the emotion management functions that guides fulfil (Holyfield, 1999; Holyfield and Jonas, 2003; Sharpe, 2005).

Emotions have been explored as adventure guiding tools, as well as determinants of tourist satisfaction and guide job satisfaction. In relation to white-water guiding specifically, Fluker and Deery (2003) suggested that river guides are motivated by positive emotions such as excitement. Holyfield (1999, p. 10) argued that river guides 'embody the excitement they are selling' while attempting to conceal anxiety or fear. These high-intensity emotions may also help negate feelings of boredom. Research has only begun to explore river guides' psychological experiences and their implications, particularly those related to unpleasant emotions of anxiety or fear.

Recent white-water tourism studies in this vein suggest that river guiding may affect guides' psychological and emotional well-being (Carnicelli-Filho, 2010, 2013; Houge Mackenzie \& Kerr, 2013a, 2013b). Carnicelli-Filho's $(2010,2013)$ research on river lifestyles explored guides' emotional experiences broadly throughout work and non-work contexts using a combination of participant observation and in-depth interviews over the course of two river seasons. The author became immersed in guides' work and non-work lives and concluded that 'because of the mixed nature of adventure guiding, where elements of work mix with elements of non-work, it seems appropriate to present Emotional Performance at Work as an element which cannot be detached from Emotional Performance at Non-Work' (Carnicelli-Filho, 2013, p. 204). In addition to encompassing emotional performances at work and non-work in his 'Emotional Life' framework, Carnicelli-Filho (2013) also included a sphere termed 'emotional simulacrum,' which involves managing emotions that originate from past, simulated, or even hypothetical events (similar to nostalgia). This study illustrated how guiding emotions permeate leisure and work settings and demonstrated that adventure guides manage emotions as much to satisfy personal expectations as organisational and client expectations. Houge Mackenzie and Kerr (2013a and 2013b) further highlighted the role of emotions at work in guide well-being through indepth autoethnographical studies of a guide's overseas work experiences. These narratives demonstrated how emotional well-being suffered when trust amongst co-guides or managers was lacking, whereas confidence in coworkers and management was associated with enhanced emotional wellbeing. These studies illuminate the importance of emotions in guide experiences, as well as unique 'familial-type' relationships amongst guides, coworkers, and employers that can dualistically enhance and/or thwart guides' well-being. The current study builds upon these findings by employing reversal 
theory constructs to analyse motivations and emotions experienced by a guide throughout a white-water tourism career, and exploring implications for adventure guides, clients, and managers.

\section{Theoretical framework: reversal theory \& the protective frame}

In addition to the need for further study of guide experiences, development and application of theoretical frameworks to interpret and understand these interactions are required. The increasing use of psychological theories in tourism over the past two decades has improved our understanding of a range of tourism issues (Pearce, 1991, 1996, 2011). For instance, strategies to improve tourism experiences (Pearce \& Stringer, 1991) and understandings of tourists' emotional experiences (Pearce, 2012) have been enhanced by the application of psychological theories. The current study employs reversal theory, an established psychological model, to guide data analysis and identify key motivational and emotional states in the guide experience, such as anxiety or fear. Reversal theory explains the structure of experience and resulting emotions by identifying opposing pairs of motivational states. It proposes that one's current frame of mind (i.e. metamotivational state) dictates how we interpret somatic feelings and interpersonal transactions (Apter, 1982, 2001), and thereby can be used to predict our emotional experiences. Thus it was expected that this psychological model would assist in understanding the dynamic nature of guide motivations and emotions. This theory has been developed across a range of disciplines including sport, exercise, and adventure recreation (Apter, 1992; Chirivella \& Martinez, 1994; Cogan \& Brown, 1999; Pain \& Kerr, 2004), but has rarely been applied or developed in tourism (Houge Mackenzie, \& Kerr, 2012).

The reversal theory 'protective frame' construct may prove highly relevant to the adventure tourism context. The protective frame provides feelings of safety from risk or danger and is generally operationalised as confidence in one's knowledge and skills, others in the guiding team, and/or equipment (Apter, 1993). With regard to adventure guides, it is reasonable to assume that the protective frames might be based on factors such as high personal skills, knowledge of safety procedures, confidence in the structure and capability of their equipment, perception that the risks involved are manageable, and a client (or group) with sufficient skills to undertake the adventure activity under guide supervision. Without a protective frame, risk-taking is experienced as anxiety and fear; however, within a frame, or protective 'psychological bubble', it feels exciting. Excitement (pleasant heightened arousal) is only possible when risk is coupled with some form of protective frame. Reversal theorists postulate that a strong, resilient protective frame is fundamental to exciting playful experiences, such as those marketed in adventure tourism. Conversely, studies highlight the negative consequences of losing a protective frame in adventure activities. In the case of one expert skydiver, the loss of a protective 
frame leads to severe anxiety, depression, complete withdrawal from the sport, and suicidal thoughts (Kerr, 2007). Thus, it would appear that developing and maintaining a strong protective frame may enhance guides' emotional wellbeing.

Reversal theory posits that the protective frame operates in one of the four opposing motivational state pairs that influence our felt emotions. These paired states are theorised to account for the experiential paradoxes that occur in everyday life, such as alternating feelings of anxiety or excitement when meeting new people or attempting novel tasks. Table 1 outlines the key characteristics of each motivational state. In the telic state, a person lacks a protective frame and feels serious, goal oriented, and arousal avoidant. In the opposing paratelic state, the protective frame is salient and the individual feels spontaneous, playful, and arousal seeking. In the conformist state, a person feels compliant and agreeable, while feeling rebellious, unconventional, and defiant in the opposing negativistic state. A person in the mastery state is competitive and dominating, while desiring harmony and cooperation in the sympathy state. A person in the autic state is egoistic and concerned with the self, while feeling altruistic and concerned with others in the alloic state. Regular reversals between these paired motivational states are postulated to produce significant changes in a person's motivations and emotional experiences. Reversal theory predicts 16 primary emotions that are produced by different combinations of motivational states (Table 2). Positive emotions result when a person's preferred way of feeling matches their current experience, whereas negative emotions occur when there is a mismatch between a person's preferred way of feeling and their current experience. Negative emotions are indicative of stress caused by this mismatch, and the prolonged experience of negative emotions may affect a person's health and psychological well-being.

Three conditions are proposed to precipitate motivational reversals and resulting changes to the protective frame and felt emotions: contingent events, frustration, and satiation (Apter, 1982). Contingent events may be internal or external (e.g. pulling a muscle, poor weather, or criticism from a co-worker). Frustration occurs when a person's needs in a particular state are not being met (e.g. a goal or activity cannot be completed in the telic state, and failure to effectively communicate with others in the alloic state),

Table 1. Proposed motivational state pairs in reversal theory.

\begin{tabular}{|c|c|}
\hline $\begin{array}{l}\text { Telic: serious, outcome oriented, arousal } \\
\text { avoidant }\end{array}$ & $\begin{array}{l}\text { Paratelic: playful, process oriented, arousal } \\
\text { seeking }\end{array}$ \\
\hline Conformist: rule abiding & Negativistic: rebellious \\
\hline Mastery: domination oriented & Sympathy: relationship oriented \\
\hline Autic: self-focused, concern for self & Alloic: other-focused, concern for others \\
\hline
\end{tabular}


Table 2. Somatic and transactional state combinations and the resulting 16 primary emotions.

\begin{tabular}{lll}
\hline State combination & \multicolumn{1}{c}{ Pleasant } & Unpleasant \\
\hline Somatic emotions & Relaxation & \\
Telic-conformity & Placidity & Anxiety \\
Telic-negativism & Excitement & Anger \\
Paratelic-conformity & provocativeness & Boredom \\
Paratelic-negativism & & sullenness \\
Transactional emotions & Pride & \\
Autic-mastery & Gratitude & humiliation \\
Autic-sympathy & Modesty & resentment \\
Alloic--mastery & Virtue & Shame \\
Alloic-sympathy & & Guilt \\
\hline
\end{tabular}

whereas reversals due to satiation result from remaining in one state for an extended period (e.g. preparing for an examination for a long period in the telic state, and continually taking orders from a superior when in the sympathy state).

\section{Research objectives}

This investigation sought to augment adventure literature by applying a novel framework and emerging methodological approach to explore the psychological experience of river guiding. Reversal theory and the protective frame construct were used to critically analyse longitudinal autoethnographical data. The study aims were to (a) present a detailed qualitative account of a river guide's psychological experiences in relation to the presence or absence of a protective frame; (b) identify factors that may influence river guides' motivational and emotional states and psychological well-being; and (c) discuss the implications of these findings for tourism professionals and researchers.

\section{Methods}

\section{Autoethnography}

'Autoethnography is a form or method of research that involves self-observation and reflexive investigation in the context of ethnographic field work and writing' (Maréchal, 2010, p. 43). Ellis (2004) defines autoethnography as 'a form of ethnography ... part auto or self and part ethno or culture' (p. 31) and describes it as 'research, writing, story, and method that connect the autobiographical and personal to the cultural, social, and political' (p. xix). The current study presents a unique autoethnographical perspective on guide experiences, in contrast to traditional quantitative or observational tourism research. 
This methodology was appropriate given the internal, psychological nature of the enquiry. A number of scholars (Anderson \& Austin, 2012; Ateljevic, Pritchard, \& Morgan, 2007; Noy, 2008) advocate for the use of autoethnography on the basis that it provides novel insights in tourism and leisure studies by illustrating the emotional complexities and contradictions inherent in these experiences. This method has been used to understand diverse tourism experiences including white-water rafting (Jonas, Stewart, \& Larkin, 2003), sea kayaking experiences (Varley, 2011), adventure tourism (Buckley, 2012), and cycling events (Coghlan, 2012).

Analytical autoethnography was the methodological approach employed in this study, which requires the use of an established theoretical model to analyse and interpret data (Anderson \& Austin, 2012; Snow, Morrill, \& Anderson, 2003). In this case, the primary researcher (the lead author) was solely responsible for data collection, after which point an additional researcher (the second author) contributed to data analysis. The researchers adhered to analytical autoethnographical principles of analytic reflexivity, narrative visibility of the primary researcher, dialogue with informants beyond the primary researcher, complete member status of the primary researcher, and commitment to theoretical analysis (Anderson, 2006). The researchers also reflected on Richardson's (2000) criteria for evaluating personal narratives during the analysis and writing stages; these included substantive contribution, aesthetic merit, reflexivity, impactfulness, and expression of a reality or lived experience.

In qualitative and autoethnographical research, trustworthiness depends upon thick descriptions of data collection, analysis, and the autoethnographer (Denzin \& Lincoln, 2005). Data analyses focused on narratives of critical incidents recorded throughout the primary researcher's 10-year white-water guiding career. Data were collected in the form of journal entries, emails, and field notes, throughout this period (approximately 800 field days). Prior to commencing her white-water career, the autoethnograher had a background in psychology and traditional competitive sports. The data reflect her experiences as a white-water riverboard guide throughout training and development, which included training, certification, guiding, and risk management processes across a range of environmental, social, cultural, and political contexts in Australasia and North and South America. These experiences included living, working, and socialising with guides and clients from six continents. Her narratives during the period of study were also shaped by completing a doctorate focused on psychological aspects of adventure; helping to develop national guiding standards for an emerging river activity; and teaching courses in adventure tourism management.

Data coding and analysis of psychological states and emotions were informed by the Metamotivational State Coding Scale (O'Connell, Potocky, Cook, \& Gerkovich, 1991). Verbatim data were initially coded for motivational states or emotions associated with internal or external factors. An example of coding related to the autic-mastery state combination and feelings of 
humiliation was the guide statement: 'I just felt useless and embarrassed as a "senior" guide and assessor who couldn't even tow a fake client across the river all while my future boss is watching.' An example of the telic-conformity state combination with anxiety coding was, 'I'm nervous because all the equipment here is different: different fins, flippers, different boards, different wetsuits.' Data were then reanalysed to detect common themes and grouped by similar themes and contexts. Final analyses were conducted to identify additional emergent themes. In line with analytic autoethnography, this approach allowed the researchers to conduct a critical, theoretical analysis of psychological constructs underlying the guide's experiences (e.g. motivational and emotional states, and reversals), as well as providing reflexive space for themes to emerge.

After the primary researcher completed her analyses, data auditing was used to minimise selective reporting and cognitive bias during data analysis. The second author, an experienced researcher in reversal theory, qualitative methods, and adventure sports, independently analysed all verbatim data in the manner outlined previously in the article. Both researchers repeatedly reviewed the entire data set to ensure that representative quotes were chosen to display common themes and patterns. As experienced qualitative researchers, the authors were aware of subjective biases in data collection and analysis processes and endeavoured to reduce these biases through reflexivity, continual self-critique, and reference to theoretical coding tools (Denzin \& Lincoln, 2005; O'Connell et al., 1991). The researchers did not identify major divergences upon comparing and discussing their analyses. Minor inconsistencies were resolved in two ways: critical probing of the autoethnographer by the second author for further contextual details and perspectives, and consulting reversal theory literature and coding tools (Apter, 2001; O'Connell et al., 1991).

\section{Results}

The results section is structured in the following manner: each of the participant guide's verbatim quotes (written in the first person) is preceded by a brief description, and followed by theoretical analysis (written in the third person). Unless otherwise indicated, the quotes grouped together in each subsection refer to different river guiding events. The reader will note that some verbatim quotes explicitly refer to reversal theory constructs, such as the protective frame or telic state. This resulted from the autoethnographer's background in psychology, including reversal theory, which allowed her to explicitly identify some motivational states and reversals as she recorded data.

Data analysis indicated that the emotional experience associated with river guiding could be intensely positive and negative, and could quickly oscillate between these two experiences as the guide's motivational states reversed. Examples of the guide's experience of positive and negative emotions, while guiding groups, are provided in the following. 


\section{Incidents 1-3: positive emotions, the protective frame, and reversals}

I like the big groups and how we have to work quickly together to manage them when the water is fast. I like the challenge of being able to manage a big group. It's more exciting especially now that I'm more familiar with the section and I'm not so worried about people getting stuck in [the big rapid] or hitting rocks ... You always feel more confident ... with three guides [on a trip]. It was more fun to see how we could get these nine [unskilled] people down the river, rather than stressful, as there were three of us, not just me.

I definitely got a thrill yesterday when I went and got a girl out of a hole, ${ }^{1}$ recovered someone else's board, and regrouped everyone in the group in about 30 seconds. You feel like superman, superwoman, in a way. It's a great feeling and I'll admit that when the group is too easy sometimes you feel bored, like you want someone to tow or to help.

I also noticed that we [guides] do like a challenge and even though safety is a priority and is paramount, I think I still get a thrill when I have to make big saves on the river and I just manage to sort the group out. When it's too much challenge, too many people going wrong, it's scary. But say you make one big save, like Luis, $^{2}$ a guy who was almost in the big hole at the bottom of [a rapid] ... He was so excited [afterward] like, 'Yeah, I did it', like an intense telic to paratelic shift. Beforehand you're so nervous just trying to get there and help someone. And then once you do it, it's great. You reverse and it's a huge thrill.

As illustrated by the aforementioned three quotes, the guide frequently experienced intense positive emotions while working. The quotes suggest feelings of confidence and mastery while navigating different groups through complex rapids, ensuring clients avoided rocks, and averting potentially dangerous holes at the bottom of rapids. Her psychological experiences during these incidents were characterised by positive hedonic tone and pleasant emotions. Excitement was experienced due to the thrill associated with guiding challenges (Incident 1). The quotes also reflect feelings of pride from working together as a team with two other guides (Incident 1) and virtue after assisting two clients (Incidents 2 and 3).

According to reversal theory, the presence of a protective frame facilitated the experience of positive emotions in these risky situations (Apter, 1992; Kerr, 2007). Incident 3 suggests how the guide's protective frame may have functioned: 'When it's too much challenge, too many people going wrong, it's scary.' In other words, in the paratelic-conformity state combination, the guide wanted some degree of challenge that she felt competent to deal with (protective frame operative), otherwise her arousal levels might drop and lead to feelings of boredom (Incident 2). However, she did not want 'too much challenge', which would change her appraisal of the situation to 'scary'. This indicated that a paratelic to telic-conformity motivational state reversal may have rendered her protective frame inoperative (Incident 3). The guide also recognised that, after assisting her client Luis, she underwent a telic to paratelic-conformity state 
reversal and her arousal level and emotional state changed from being moderately anxious (nervous) to one of high arousal excitement and feelings of 'thrill'. It is interesting to note that the guide's telic to paratelic state reversal appeared to be accompanied by a similar reversal in the client.

\section{Incident 4: negative emotions, absence of the protective frame, and reversals}

This quote highlights the guide's negative emotional experiences during a fourday training trip prior to working for a river adventure company. Unbeknownst to the guide, the training included sections of grade 5-6 rapids, which are only recommended for individuals with advanced white-water skills at appropriate water levels.

I'm not ashamed to say that in the past four days I have had some of the most terrifying experiences of my life. Our first day, we set out at 5:45 am to run a grade 5 river in snow and hail... Our second day we ran a grade 5 plus called ... 'Upper Death' followed directly by 'Life after Death'. When we arrived at the river, we met an experienced kayaker who said we were crazy to run these rapids, but offered to run safety from the bank. He stood at the bottom of the rapid to throw us a rope, which wouldn't have helped because when we did run it (I must have lapsed into another dimension of stupidity to do it; I still don't know how I did ... ), I entered the first drop and disappeared... [on the video] I am not seen again until popping up backwards and sideways, briefly ... Then I disappear again as I hit the final drop (the biggest) and the two guys who were behind me both surface before you can see my yellow board again. The first thing I saw when I surfaced was the kayaker whose eyes were popping out in shock, cartoon-style. And that was only Upper Death.

This four-day trip was unpleasant for the guide and she summed it up as 'having some of the most terrifying experiences of my life'. This quote illustrated that, when running rapids at this level of difficulty, her high arousal level was interpreted as intense anxiety, or extreme fear. Her overall hedonic tone was negative and remained negative throughout the experience; there is no statement to suggest that she might have reversed to a pleasant motivational state at any time. Running these particular rapids exceeded her capabilities and, with the kayaker acting as an ineffective 'safety' system on the riverbank, she felt that the challenge was too great for her. As a result, her protective frame never became operative (Apter, 1992). Although the protective frame may increase the likelihood of positive emotional experiences while guiding, this incident illustrated how negative emotions may be useful and highly adaptive in a guiding context. The negative emotions that ensue in high-risk situations when the protective frame is lacking may provide important cues to guides regarding what obstacles pose risks that exceed their capabilities. Instead of seeking to overcome her negative emotions in this instance, the guide may have perhaps been better served by heeding them. In addition to the aforementioned example, there 
were a number of factors associated with guiding river groups that led to negative experiences. Some of these are explored in detail in the subsections that follow.

\section{Incidents 5 and 6: management procedures}

The first quote in this subsection is an example of how one company's unsafe procedures caused a negative emotional experience for the guide. The second quote illustrates how her feelings about these risky procedures eventually resulted in her leaving the company.

This week as part of guide training [Tim] took me to a technical nine-mile grade four section I had never seen before and made me 'read and run' ${ }^{3}$ the entire thing. I led the entire nine miles without being allowed to scout anything from the bank. On a river board, this means deciding what line to take with your head two feet above the water and very limited visibility of rapids and hazards [ahead]. Although I am sure I improved my river skills, the entire experience was incredibly nerve-wracking.

This experience has been very emotionally draining because I tried so hard to do well at this job and I love [this town]. I have done so many more dangerous things on the river this season than I ever would have otherwise and finally decided that enough is enough. But I still feel bad leaving the company, as though it's my fault for not being 'tough' enough or something, because that's what [Tim] will say. He will say that I was too sensitive or not 'hard core' enough when really I just cannot safely work for him and would be amazed to find out who can. I have to leave not only because of how poorly he treats his guides, especially me as the only female, but primarily for safety reasons. I just don't trust his decisions and don't feel safe on the river with him.

In Incident 5, the guide's statements show her discomfort with Tim's guide training exercise. It is common practice to scout river sections, especially difficult rapids, from the riverbank. This provides the guide with an elevated view from which he or she can plan a route through rocks or other features and identify any hazards to avoid. This preparation work contributes to the guide's selfconfidence and mastery of the situation. The inability to do this induced the telic-conformity state combination and feelings of anxiety with accompanying unpleasant high arousal (the entire experience was incredibly nerve-wracking). Under these conditions, she was unable to experience the training exercise with an operative protective frame or positive emotions. There were a number of similar incidents that led her to re-evaluate her position with the company. Incident 6 statements underscore her anxiety-based comments from Incident 5, and indicate that she was unsure and untrusting of the management's decisionmaking and procedures. A lack of empathy between the manager and the guide appeared to foster unpleasant interpersonal transactions and resulted in the autic-sympathy state accompanied by feelings of resentment. Despite her safety concerns, the guide also felt guilty leaving the company. This suggests 
that reversals from the autic-sympathy to the alloic-sympathy state combination may have occurred while guiding, which replaced her unpleasant feelings of resentment with equally unpleasant feelings of guilt.

\section{Incidents 7 and 8: protective frames, decision-making, and client safety}

During the drive back to base or after cleaning the equipment, the guide reflected on both positive and negative aspects of each trip. This reflection occurred through conversations with other guides as well as a personal diary. The following quotes exemplify common post-trip reflections on key trip elements, such as what occurred, how the guides performed, and how she felt about particular groups, individuals, and situations.

After the last trip, I was so worried I was a terrible guide and that something horrible might have happened, which is actually a good experience for every guide to have. But at the same time, I really need to redeem my personal confidence, that protective frame, in order to be a good guide. If I can't trust myself, how can I expect other people to trust me?

We had a great trip although I made a bad decision in [a technical rapid] by not going to get two clients on the right side... What upset me most about this was that it was because I was nervous. I have a fear of the right side of that rapid... I still don't know it that well ... because of that, I didn't look after my clients as well as I should have. No one else was upset, as the kayaker [assisted] them and I don't think anyone even really noticed, but... I hate admitting that I feel fear. It almost feels like a big weakness as a guide. I'm meant to be fearless and some kind of 'hero' and the clients think you are. 'Oh, you saved my life', they say. But I hate to admit that there are sometimes... where self-preservation kicks in and I don't put my body on the line all the time for my clients as I should do... Rather I make sure I get myself to the good line and clean up the mess. This is not always the case, but there are a few rapids in which I won't follow a client just anywhere. I feel I need to look after myself first. But then I always feel guilty, like I've shown weakness and not done my job.

The importance of a strong protective frame is emphasised by Incident 7. Although the protective frame generally appeared operative while the guide was on the river, data indicated she lacked this frame in relation to specific hazards or sections. In Incident 8, the guide stated that she was afraid of the right-hand side of a difficult rapid, and that this negative emotion had affected her duty of care for clients. In reversal theory terms, approaching the right-hand side of the rapid induced the telic-conformity state combination and the guide became anxious and fearful. With her protective frame inactive during this particular rapid, she did not feel in control of the situation or competent enough to effectively assist clients (Kerr, 1997). The guide elaborated that there were some river locations where she had put her own safety before the clients' safety (Incident 8). Both incidents suggest that 
client safety could be severely compromised as a result of guides' motivational and emotional state changes. According to reversal theory, the guide felt she provided good care for her clients in alloic and sympathy states characterised by other-focused, altruistic motivation. Not only did certain river features appear to induce paratelic to telic state reversals, but they also appeared to instigate alloic-sympathy to autic-mastery reversals, characterised by selfpreservation and mastery motivations. The guide's feelings of guilt and statements that she had failed in her duties to clients suggested a rapid reversal back to alloic-sympathy states following these incidents. The absence of a protective frame, along with feelings of personal failure, indicated that negative emotions and poor hedonic tone also ensued.

\section{Incidents 9 and 10: client interactions}

In order to ensure group safety on river trips, particularly on river boarding trips in which clients are on individual boards, it is important that clients follow instructions. Often clients do not understand or simply forget instructions but, occasionally, they may ignore or disobey instructions. This is what occurred in Incident 9 that follows:

I was a bit stressed by two ... brothers who were playing around, not listening, going off line, and slowing down at the back. This pisses me off the most as a guide because I have loads of time and patience for clients who are just uncoordinated but are listening and trying ... Clients that don't listen and are generally strong in the water, but endanger the group by not sticking together, drive me crazy. That was exactly the case today. The brothers [were] going backwards, [the] wrong way, standing on rocks, and spreading the group out so I couldn't ... look after everyone. This issue came to a head above one of our biggest rapids ... I was towing two girls who were struggling ... At one point I actually yelled, 'Get back on your [expletive] board!' I was so angry with them.

...you won't believe what happened ... on the river yesterday. A client actually hit me and yelled at me to '[expletive] off' and do my job! I'll back up - a guy ... showed up for the trip and started telling me about all the rivers he had been down in South America... So I assumed he would be a good client and not too much trouble. Once the trip started, he kept hanging at the back of the group and getting behind me, so I went over and tried to get him ... [to] keep the group together ... the third time I tried to grab the handle on his board to tow him forward ... he started hitting my hands and arms and swearing at me - and told me to '[expletive] off and do my job!' I was so shocked and upset that I left him behind, but signalled to my boss ... to pull the group over. I actually started to cry a little bit out of shock, which thank god no one noticed, but I felt totally embarrassed and upset.

In Incident 9, two brothers ignored the guide's instructions and endangered other members of the group. The guide's ensuing experience of negative emotions started with her initially feeling annoyed at their behaviour, but 
these feelings quickly escalated into anger and anxiety as arousal levels increased with the telic and negativistic states operative (Apter, 1982, 2001). In Incident 10, the guide was the recipient of verbal and physical aggression from a client, which left her feeling shocked and upset. Reversal theorists would classify the client's actions as a sudden environmental event that induced the telic-conformity state combination with high arousal, thus breaking the guide's protective frame and leaving her feeling highly anxious and possibly fearful (shocked and upset). In addition, her embarrassment suggests she was in an autic-mastery state combination. However, instead of feeling pride in her professional guiding efforts, which would normally result from this state combination, she was left feeling humiliated and embarrassed by the interaction with the client (Kerr, 1997).

\section{Incidents 11 and 12: changing unpleasant emotions through reversals}

Research has shown that in order to promote good client relations on river adventure trips, guides must present the activities as exciting and thrilling and conceal any anxiety or fear that they may experience (Fluker \& Deery, 2003; Holyfield, 1999). It has also been argued that guides modulate their own emotions, in addition to deliberately boosting clients' positive affect (Holyfield et al., 2005). Given that the current data highlighted a number of factors linked to negative guide emotions, the researchers also sought to identify instances in which the guide may have manipulated her motivational state to induce reversals, and thereby experience positive emotions. The following incidents illustrated how the guide appeared to successfully manipulate her emotions:

Today, with the rain, you just don't feel motivated and I wanted to get the trip over as soon as possible (telic) and get out, as I felt so cold in the river. During the trip, after I warmed up, I think I reversed to being paratelic and once I was really engaged in the guiding that's how I felt - excited, engaged. But at the start and the end, I just wanted to get it over with, have a hot shower, and get into some warm clothes.

I was rushing all the clients to get dressed - I later realised they had mistaken for me having fun and being 'extreme', rather than short on time. I was rushing them with a big smile on my face so as not to be rude. But they just thought I was a bit of a crazy guide ... Once we finally got everyone dressed and into the river, I was still rushing, but I think I had relaxed a bit. I think the pure act of having to act happy and enthusiastic forced me to become more immersed in my job and actually feel that way. Once I was doing it, I wasn't so worried about getting back on time. I had an immediate job to do and that was all that mattered.

Incident 11 indicates that weather conditions may influence guide motivations and emotions. In this case, the guide initially recognised that she was in the serious telic state due to poor weather and river conditions, wherein she just 
wanted to complete her trip as quickly as possible. However, once she 'really engaged in the guiding' she appeared to reverse to a playful paratelic state characterised by excitement. The data also suggest that she may have reversed back to the telic state at the end of the trip because she 'just wanted to get it over with'. In Incident 12, she was rushing the group while feigning positive emotions. An unexpected result of this 'surface acting' was that she reduced her arousal levels and felt pleasant relaxation. The guide reflected that 'I think the pure act of having to act happy and enthusiastic forces you to become more immersed in your job and actually feel that way.' Reconceptualising a situation is one of the strategies recognised in reversal theory for inducing reversals (Desselles \& Apter, 2013). In this case, there is no statement indicating a reversal, but this technique appeared to effectively reduce her arousal levels and allow her to experience pleasant relaxation instead of unpleasant anxiety in the telic-conformist state.

\section{Discussion and implications}

The results of this study complement previous ethnographic studies of adventure tourism experiences (Arnould \& Price, 1993; Arnould et al., 1999; Buckley, 2010; Jonas, 1999) and may provide insights for tourism researchers, adventure guides, or tourism managers. Data suggested that river guiding involves intense, dynamic positive and negative emotional experiences. Interestingly, key aspects of the guide experience, such as exams and training; interactions with clients, other guides, and managers; safety issues; equipment; and river features and hazards, appeared to alternately cause both intense positive and negative emotions. For example, client interactions were reported to cause anxiety as well as excitement and enjoyment. Data also suggested that, regardless of the context, the presence or absence of a protective frame may have influenced whether these external factors were interpreted positively or negatively. There were a range of factors that seemed to influence the protective frame, including guide confidence in personal skills; the river environment; trust, confidence, and personal relationships with management and other guides; guide to client ratios; client behaviour; weather; trip logistics; and the relative matching of perceived challenge and skill levels during training and while guiding.

One noteworthy finding is that the guide frequently experienced fear and anxiety during her training and guiding experiences. Contrary to heroic expectations and perceptions of guides as fearless 'river gods' that permeate popular and research literature (Carnicelli-Filho, 2010; Holyfield \& Jonas, 2003), this study suggests that at least a subset of adventure guides do not fit this profile. Rather, data indicated that the process of becoming and embodying a 'river guide' can be wrought with intense positive and negative emotions, which guides must continually manage to maintain well-being and deliver safe services for clients. Data suggested that guides need to simultaneously build 
skills and regulate challenge levels to ensure that they are optimally engaged, and avoid the extreme emotions of boredom or anxiety that could detract from psychological well-being, contribute to poor decision-making, and potentially lead to burn out.

These findings are supported by research in reversal theory and flow theory, which documents that optimal challenge levels promote enjoyment, intrinsic motivation, and long-term engagement in an activity (Csikszentmihalyi, 2000; Rea, 1993). Recent findings suggest that the protective frame and reversals within the telic-paratelic state pair may play a pivotal role in optimal 'flow' experiences. Specifically, engagement amongst river guides may be optimised when personal skills exceed, rather than match, challenge levels in a state of telic flow (Houge Mackenzie et al., 2011, 2013). This has direct implications for guide well-being as flow states (i.e. optimal engagement in an activity) contribute to creativity, performance, meaningfulness, life satisfaction, and wellbeing in work and leisure settings (Demerouti, 2006; Edginton, Jordan, DeGraaf, \& Edginton, 1995; Haworth \& Hill, 1992; May, Gilson, \& Harter, 2004). The current study findings contribute to this body of knowledge and help develop current notions and models of 'optimal experiences' and wellbeing in guiding contexts.

Another theme that emerged during analysis, which runs somewhat contrary to the emotional labour literature, was the finding that 'surface acting' (Van Dijk, Smith, \& Cooper, 2011) may improve psychological well-being in some instances. Data suggested that despite the guide sometimes feeling negative emotions at the outset of a trip, the necessity of acting happy and positive for clients could facilitate positive emotional reversals. The guide reported how, after she began smiling and acting enthusiastic, she began to actually feel that way. As a result, she became immersed in her immediate tasks, rather than peripheral concerns, which may have led to motivational reversals that transformed her emotional experiences. Although this phenomenon has yet to be discussed in tourism literature that mainly focuses on negative impacts of emotional labour, psychological literature indicates that changes in facial expressions and body language can alter emotional states (Carney, Cuddy, \& Yap, 2010). For example, studies have shown that people forced to smile, or unable to frown, are happier and less anxious than those who are forced, or able to, frown (Wenner, 2009). This research suggests that emotional acting could potentially enhance guides' experiences and mitigate negative emotions in certain contexts.

Reversal theory models support these findings. A range of techniques have been shown to help induce motivational reversals, and thereby enhance emotional experiences. Strategies include adopting different perspectives on a situation, using visual images to trigger reversals to specific states, following ritual actions or pre-activity routines, using a small item or 'prop' that is associated with a particular state, or simply changing the environment or situation (Desselles \& Apter, 2013; Kuroda, Thatcher, \& Thatcher, 2011; Thatcher, 
Kuroda, Legrand, \& Thatcher, 2010). Guides can enhance their psychological experiences by practicing and employing these strategies on a regular basis. Managers could also support this process by educating guides on these strategies and how their mental and physical actions can enhance (or detract) from personal well-being, as well as client experiences.

This study suggests that it is critically important for adventure tourism operators to actively contribute to the development of guides' protective frames through holistic training programmes, continual professional development, positive communication, and the incremental introduction of new environmental challenges and responsibilities. Guides and managers may find it useful to conceptualise 'challenges' in a number of ways, such as co-guides, management, new equipment or procedures, the environment, weather, and client groups. All of these factors may interact to determine the perceived challenge levels and the presence or absence of a guide's protective frame. For instance, a guide may have confidently worked on a grade 4 section for many years; however, changes in river features or the introduction of new client groups, co-guides, management policies, and/or equipment may remove their normally salient protective frame. This in turn could affect their performance, motivations, and emotional experiences. Thus, both guides and management may benefit from developing effective strategies to manage the range of factors that may interact to create (or destroy) guides' protective frames.

A central implication of these findings is that guides' emotional states, performance, and decision-making may be compromised if guides lack a protective frame. Therefore, management of internal and external factors influencing the protective frame could benefit guide development, performance, well-being, and long-term success, as well as client safety and enjoyment. Managers and guides could support the formation of resilient protective frames through strategies such as incremental and organised training programmes, shadowing and mentoring, mental skill training, fostering positive relationships amongst guides and management (on and off the water), and continued training and professional development opportunities. In addition, empowering guides with the autonomy and authority to make their own safety decisions without fear of reprisals from management may facilitate this process, as well as enhancing guide and client well-being and service quality.

\section{Limitations}

Every research methodology has inherent limitations regarding the conclusions that can be drawn from that data set. Autoethnography sacrifices breadth for depth by providing detailed, authentic data from a single individual who, in this case, was an informed insider with a large volume of experiences to drawn upon. Although this approach yielded novel data that may broaden tra-

ditional perspectives generally presented in tourism literature, it also has 
limitations. The guide's insider status and dual role as a psychological researcher may have limited other interpretations and analyses. For example, guides of different cultural backgrounds, genders, or activities may have vastly different experiences than the one presented here. Notwithstanding, this study provides an underrepresented perspective in adventure tourism studies: a subjective, prospective account recorded by a female adventure guide longitudinally throughout her career. The unique psychological analysis of these autoethnographical data provides valuable information for researchers and practitioners alike that could not be obtained through traditional positivist methodologies. This investigation provides a nuanced account of an adventure guide's lived experience and turns the research lens on the guide, rather than the tourist, in an effort to address knowledge gaps in the tourism literature. This study provides an emergent perspective in tourism literature, in terms of both theory and content. Examining and recognising the importance of guide voices and narratives have the potential to enhance tourism practices and theoretical approaches.

\section{Conclusion}

The results of the current study have relevance for adventure tourism professionals and scholars. Managers should cultivate awareness of, and concern for, the psychological states of guiding staff as these may influence guide well-being and client experiences. In adventure activities that involve heightened levels of risk and critical safety concerns (Buckley, 2010), guide wellbeing is critically important. The data highlighted instances in which safety and client experiences may have been negatively impacted when the guide's protective frame failed and negative emotions ensued. Conversely, when the guide's protective frame was active, her emotional experience, customer service, and safety appeared to be enhanced. This study highlights the potential influence of guides' psychological states and emotions in facilitating consistently optimal performance and retention of skilled guides.

On a theoretical level, the current study highlights how reversal theory may contribute to our understanding of guide experiences. This psychological model helps to identify psychological states (e.g. the protective frame) that may influence guide experiences and decision-making. Identifying key factors that influence the protective frame could facilitate improved prediction of psychological patterns and assist in the development of guide training and management strategies. As demonstrated most notably by Pearce $(1991,2011)$, tourism research can benefit from the integration of psychological models to enhance research approaches and provide applied strategies for improvement. The current study complements tourism literature by providing a longitudinal autoethnographical account of guide experiences and emotions. It also employs a unique psychological framework (reversal theory) and methodological approach to investigate and explain psychological factors that may influence guide well-being. 
Finally, this study highlights the potential importance of the protective frame in guide performance, suggests practical strategies to enhance emotional experiences, and identifies fruitful avenues of future study in this area.

\section{Funding}

This work was supported by the California State University Agricultural Research Initiative Seed Grant.

\section{Notes}

1. A hole (also known as a hydraulic) is a white-water river feature that forms as the river flows over an obstruction that is near or above the surface of the water. As the water flows over the obstruction, it creates aerated water that flows back upstream and recirculates river crafts or people in a motion similar to a washing machine. Depending on the strength of the hole, river crafts or people may be unable to escape this recirculating water.

2. All names are pseudonyms.

3. 'Reading and running' refers to the practice of deciding on the best route down a river while travelling downstream, without getting out of the river and 'scouting' or assessing the best line of travel from an elevated viewpoint on the riverbank. Generally, assessing the best line of travel from the riverbank is a safer practice, especially for more challenging rapids.

\section{References}

Anderson, L. (2006). Analytic autoethnography. Journal of Contemporary Ethnography, 35, 373-395.

Anderson, L., \& Austin, M. (2012). Auto-ethnography in leisure studies. Leisure Studies, 31(2), 131-146.

Ap, J., \& Wong, K. F. (2001). Case study on tour guiding: Professionalism, issues and problems. Tourism Management, 22(5), 551-563.

Apter, M. J. (1982). The experience of motivation: The theory of psychological reversals. London: Academic Press.

Apter, M. J. (1992). The dangerous edge: The psychology of excitement. New York: Free Press.

Apter, M. J. (1993). Phenomenological frames and the paradoxes of experience. In J. H. Kerr, S. J. Murgatroyd, \& M. J. Apter (Eds.), Advances in reversal theory (pp. 27-39). Amsterdam: Swets \& Zeitlinger.

Apter, M. J. (Ed.). (2001). Motivational styles in everyday life: A guide to reversal theory. Washington, DC: American Psychological Association.

Arnould, E., \& Price, L. (1993). River magic: Extraordinary experience and the extended service encounter. Journal of Consumer Research, 20, 24-45.

Arnould, E., Price, L., \& Otnes, C. (1999). Making magic consumption: A study of white-water river rafting. Journal of Contemporary Ethnography, 28, 33-68.

Ateljevic, I., Pritchard, A., \& Morgan, N. (Eds.). (2007). The critical turn in tourism studies: Innovative research methodologies. Oxford: Elsevier.

Bangs, C., \& Kallen, C. (1989). Riding the dragon's back: The race to raft the upper Yangtze. New York: Atheneum. 
Brymer, E., \& Gray, T. (2010). Developing an intimate 'relationship' with nature through extreme sports participation. Loisir, 34(4), 361-374.

Brymer, E., \& Oades, L. (2009). Extreme sports: A positive transformation in courage and humility. Journal of Humanistic Psychology, 49(1), 114-126.

Brymer, E., \& Schweitzer, R. (2012). Extreme sports are good for your health: A phenomenological understanding of fear and anxiety in extreme sport. Journal of Health Psychology, online version. doi:10.1177/1359105312446770

Buckley, R. (2010). Communications in adventure tour products: Health and safety in rafting and kayaking. Annals of Tourism Research, 37(2), 315-332.

Buckley, R. (2012). Rush as a key motivation in skilled adventure tourism: Resolving the risk recreation paradox. Tourism Management, 33(4), 961-970.

Burr, J. F., Montelpare, W. J., \& Shephard, R. J. (2013). Do adventure sports have a role in health promotion? Need for objective evidence for a risk-benefit analysis. Canadian Family Physician, 59(12), 1311-1313.

Carney, D. R., Cuddy, A. J., \& Yap, A. J. (2010). Power posing brief nonverbal displays affect neuroendocrine levels and risk tolerance. Psychological Science, 21(10), 1363-1368.

Carnicelli-Filho, S. (2010). Rafting guides: Leisure, work and lifestyle. Annals of Leisure Research, 13(1-2), 282-297.

Carnicelli-Filho, S. (2013). The emotional life of adventure guides. Annals of Tourism Research, 43, 192-209.

Carnicelli-Filho, S., Schwartz, G. M., \& Tahara, A. K. (2010). Fear and adventure tourism in Brazil. Tourism management, 31(6), 953-956.

Cater, C. I. (2006). Playing with risk? Participant perceptions of risk and management implications in adventure tourism. Tourism Management, 27(2), 317-325.

Chirivella, E. C., \& Martinez, L. M. (1994). The sensation of risk and motivational tendencies in sports: An empirical study. Personality and Individual Differences, 16(5), 777-786.

Coble, T. G., Selin, S. W., \& Erickson, B. B. (2003). Hiking alone: Understanding fear, negotiation strategies and leisure experience. Journal of Leisure Research, 35(1), $1-22$.

Cogan, N., \& Brown, R. (1999). Metamotivational dominance, states and injuries in risk and safe sports. Personality and Individual Differences, 27(3), 503-518.

Coghlan, A. (2012). An autoethnographic account of a cycling charity challenge event: Exploring manifest and latent aspects of the experience. Journal of Sport \& Tourism, 17(2), 105-124.

Cohen, E. (1985). The tourist guide: The origins, structure and dynamics of a role. Annals of Tourism Research, 12(1), 5-29.

Csikszentmihalyi, M. (2000). Beyond boredom and anxiety: Experiencing flow in work and play (25th Anniversay Edition ed.). San Francisco, CA: Jossey-Bass.

Cutler, S. Q., \& Carmichael, B. A. (2010). The dimensions of the tourist experience. In M. Morgan, P. Lugosi, \& B. Ritchie (Eds.), The tourism and leisure experience: Consumer and managerial perspectives (pp. 3-26). Bristol: Channel View Publications.

Demerouti, E. (2006). Job characteristics, flow, and performance: The moderating role of conscientiousness. Journal of Occupational Health Psychology, 11(3), $266-280$.

Denzin, N. K., \& Lincoln, Y. S. (Eds.). (2005). The Sage handbook of qualitative research (3rd ed.). Thousand Oaks, CA: Sage.

Desselles, M. L., \& Apter, M. J. (2013). Manipulating motivational states: A review. Journal of Motivation, Emotion and Personality, 1(1), 44-49. 
Edginton, C. R., Jordan, D. J., DeGraaf, D. G., \& Edginton, S. R. (1995). Leisure and life satisfaction. In Leisure and life satisfaction: Foundational perspectives. Madison, WI: Brown \& Benchmark.

Ellis, C. (2004). The ethnographic I: A methodological novel about autoethnography. Walnut Creek, CA: AltaMira Press.

Fluker, M. R., \& Deery, M. (2003). Condoms in the first aid kit: River guides, clients, and sex. In T. G. Bauer \& B. McKercher (Eds.), Sex and tourism: Journeys of romance, love, and lust (pp. 109-118). Binghamton, NY: The Haworth Press.

Fluker, M. R., \& Turner, L. W. (2000). Needs, motivations, and expectations of a commercial whitewater rafting experience. Journal of Travel Research, 38(4), 380-389.

Haworth, J. T., \& Hill, S. (1992). Work, leisure, and psychological well-being in a sample of young adults. Journal of Community \& Applied Social Psychology, 2(2), 147-160.

Holyfield, L. (1999). Manufacturing adventure: The buying and selling of emotions. Journal of Contemporary Ethnography, 28, 3-32.

Holyfield, L., \& Jonas, L. (2003). From river god to research grunt: Identity, emotions, and the river guide. Symbolic Interaction, 26(2), 285-306.

Holyfield, L., Jonas, L., \& Zajicek, A. (2005). Adventure without risk is like Disneyland. In S. Lyng (Ed.), Edgework: The sociology of risk-taking (pp. 173-185). New York: Routledge.

Houge Mackenzie, S., Hodge, K., \& Boyes, M. (2011). Expanding the flow model in adventure activities: A reversal theory perspective. Journal of Leisure Research, 43(4), 519-544.

Houge Mackenzie, S., Hodge, K., \& Boyes, M. (2013). The multi-phasic and dynamic nature of flow in adventure experiences. Journal of Leisure Research, 45(2), $214-232$.

Houge Mackenzie, S., \& Kerr, J. H. (2012). A (mis) guided adventure tourism experience: An autoethnographic analysis of mountaineering in Bolivia. Journal of Sport \& Tourism, 17(2), 125-144.

Houge Mackenzie, S., \& Kerr, J. H. (2013a). Can’t we all just get along? Emotions and the team guiding experience in adventure tourism. Special edition of Journal of Destination Marketing and Management, 2(2), 85-93.

Houge Mackenzie, S., \& Kerr, J. H. (2013b). Stress and emotions at work: Adventure tourism guiding experiences in South America. Tourism Management, 36, 3-14.

Jonas, L. (1999). Making and facing danger: Constructing strong character on the river. Symbolic Interaction, 22(3), 247-267.

Jonas, L. M., Stewart, W. P., \& Larkin, K. W. (2003). Encountering Heidi: Audiences for a wilderness adventurer identity. Journal of Contemporary Ethnography, 32, 403-431.

Kerr, J. H. (1997). Motivation and emotion in sport: Reversal theory. Hove: Psychology Press.

Kerr, J. H. (2007). Sudden withdrawal from skydiving: A case study informed by reversal theory's concept of protective frames. Journal of Applied Sport Psychology, 19(3), 337-351. doi:10.1080/10413200701342699

Krakauer, J. (1997). Into thin air: A personal account of the Mount Everest disaster. New York: Random House.

Kuroda, Y., Thatcher, J., \& Thatcher, R. (2011). Metamotivational state and dominance: Links with EMG gradients during isokinetic leg extension and a test of the misfit effect. Journal of Sport Sciences, 29(4), 403-410.

Lupton, D., \& Tulloch, J. (2002). 'Life would be pretty dull without risk?': Voluntary risk-taking and its pleasures. Health, Risk \& Society, 4(2), 113-124. 
Lyng, S. (1990). Edgework: A social psychological analysis of voluntary risk taking. The American Journal of Sociology, 95(4), 851-886.

Mak, A., Wong, K., \& Chang, R. (2011). Critical issues affecting the service quality and professionalism of the tour guides in Hong Kong and Macau. Tourism Management, 32, 1442-1452.

Maréchal, G. (2010). Autoethnography. In A. J. Mills, G. Durepos, \& E. Wiebe (Eds.), Encyclopedia of case study research (Vol. 2, pp. 43-45). Thousand Oaks, CA: Sage Publications.

May, D. R., Gilson, R. L., \& Harter, L. M. (2004). The psychological conditions of meaningfulness, safety and availability and the engagement of the human spirit at work. Journal of Occupational and Organisational Psychology, $77(1), 11-37$.

Noy, C. (2008). The poetics of tourist experience: An autoethnography of a family trip to Eilat. Journal of Tourism and Cultural Change, 5(3), 141-157.

O’Connell, K. A., Potocky, M., Cook, M. R., \& Gerkovich, M. M. (1991). Metamotivational state interview and coding schedule instruction manual. Kansas City, MO: Midwest Research Institute.

Pain, M. T., \& Kerr, J. H. (2004). Extreme risk taker who wants to continue taking part in high risk sports after serious injury. British Journal of Sports Medicine, 38, 337-339.

Pearce, P. L. (1991). Introduction: The tourism psychology conversation. Australian Psychologist, 26(3), 145-146.

Pearce, P. L. (1996). Recent research in tourist behaviour. Asia Pacific Journal of Tourism Research, 1(1), 7-17.

Pearce, P. L. (2011). Tourist behaviour and the contemporary world. Bristol: Channel View Publications.

Pearce, P. L. (2012). Tourists' written reactions to poverty in southern Africa. Journal of Travel Research, 51, 154-165.

Pearce, P. L., \& Stringer, P. F. (1991). Psychology and tourism. Annals of Tourism Research, 18(1), 136-154.

Pomfret, G. (2012). Personal emotional journeys associated with adventure activities on packaged mountaineering holidays. Tourism Management Perspectives, $4,145-154$.

Pond, K. (1993). The professional guide: Dynamics of tour guiding. New York: Van Nostrand Reinhold.

Rea, D. (1993). Reversal theory explanations of optimal experience. In J. H. Kerr, S. J. Murgatroyd, \& M. J. Apter (Eds.), Advances in reversal theory (pp. 75-88). Amsterdam: Swets \& Zeitlinger.

Richardson, L. (2000). Evaluating ethnography. Qualitative Inquiry, 6(2), 253-255.

Sharpe, E. K. (2005). 'Going above and beyond': The emotional labor of adventure guides. Journal of Leisure Research, 37, 29-50.

Snow, D., Morrill, C., \& Anderson, L. (2003). Elaborating analytical ethnography: Linking fieldwork and theory. Ethnography, 4(2), 181-200.

Thatcher, J., Kuroda, Y., Legrand, F., \& Thatcher, R. (2010). Stress responses during aerobic exercise in relation to motivational dominance and state. Journal of Sports Sciences, 29(3), 299-306.

Valkonen, J. (2009). Acting in nature: Service events and agency in wilderness guiding. Tourist Studies, 9(2), 164-180.

Van Dijk, P., Smith, L., \& Cooper, B. (2011). Are you for real? An evaluation of the relationship between emotional labour and visitor outcomes. Tourism Management, $32(1), 39-45$. 
Varley, P. (2011). Sea kayakers at the margins: The liminoid character of contemporary adventures. Leisure Studies, 30(1), 85-98.

Weber, K. (2008). Outdoor adventure tourism: A review of research approaches. In M. Weed (Ed.), Sport \& tourism: A reader (pp. 57-70). New York: Routledge.

Wenner, M. (2009). Smile! It could make you happier. Scientific American Mind, 20(5), $14-15$.

Williams, P., \& Soutar, G. N. (2009). Value, satisfaction and behavioral intentions in an adventure tourism context. Annals of Tourism Research, 36(3), 413-438.

Willig, C. (2008). A phenomenological investigation of the experience of taking part in 'extreme sports'. Journal of Health Psychology, 13(5), 690-702. 